\title{
Assessment of an Evaluation Approach for Malodorous Rivers
}

\author{
Huixia Jin ${ }^{1,}$, Dongxia Zhang ${ }^{1, b}$, Lifei Ye ${ }^{2, c}$, Qing Yang ${ }^{1, d}$, \\ Kefeng Zhang ${ }^{1, \mathrm{e}^{*}}$ \\ ${ }^{1}$ School of Civil Engineering and Architecture, Ningbo Institute of Technology, Zhejiang University, \\ Ningbo, 315100, China \\ ${ }^{2}$ Bureau of Urban Management, Yinzhou District, Ningbo, 315100, China

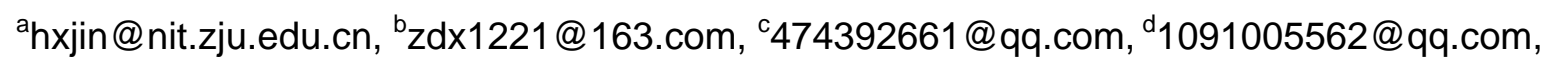 \\ ekfzhang@nit.zju.edu.cn
}

Keywords: River monitoring, polluted rivers, water quality, malodorous rivers, assessment approach.

Abstract. Urban river systems have increasingly become polluted in China due to rapid industrialization and urbanization. Although there are standards for classification of surface water in terms of water quality, no classification exists for malodorous rivers. In this study we used a combined approach of quantitative index and sensory evaluation for assessing heavily polluted river water. Two urban rivers in Ningbo, China were selected to test the proposed approach. Results showed that the quantitative index based on the measured concentration of chemical oxygen demand, ammonia nitrogen and dissolved oxygen agreed well the sensory evaluation, indicating that the proposed approach could effectively be used for evaluating malodorous rivers.

\section{Introduction}

In recent years, as a result of continuous improvement of people's living standards and the acceleration of the urbanization process, urban river systems have been heavily polluted in China, and sequentially some rivers have become malodorous. The principal reasons causing malodorous rivers are the lack of oxygen and the accumulation of organic matter in water induced by industrial and domestic sewage discharge and by the river dynamics such as immobile water [1-6].

According to the Environmental Quality Standard for Surface Water (GB 3838-2002), surface water is classified as Grade I, II, III, IV, V and inferior Grade V. Malodorous water is uniformly classified as inferior Grade V. Although there have been some studies on the further classification of malodorous rivers, there is no universally accepted evaluation criteria [7, 8]. The National Environmental Quality Status Bulletin [9] revealed that up to $23 \%$ of rivers were classified as inferior Grade $\mathrm{V}$ in the main tributaries in 2004. Overall the situation of water pollution in China remains extremely serious.

Currently there are two evaluation indices commonly used in China for the classification of malodorous rivers. One uses a single index, such as TO, $\mathrm{CH}$ together with $\mathrm{pH}, \mathrm{BOD}$ and COD, while the other uses the comprehensive index via weighted factors controlling water quality [10, 11]. The evaluation method using the single index is simple, but it cannot quantify the degree of discoloration and odor in water.

In this study, we employed the comprehensive index approach together with the sensory evaluation to assess malodorous rivers. Two urban rivers in Ningbo, China were selected to verify whether such an evaluation system was feasible, and hopefully to provide a theoretical basis for the treatment of polluted river water.

\section{Materials and Methods}

Comprehensive index for malodorous rivers. The comprehensive index for malodorous rivers employed in this study was proposed by $\mathrm{Xu}$ et al. [12]. The factors used in calculating the comprehensive index included Chemical Oxygen Demand $\left(\mathrm{COD}_{\mathrm{Mn}}\right)$, Ammonia nitrogen $(\mathrm{NH} 3-\mathrm{N})$ and Dissolved Oxygen (DO) in water. Ammonia nitrogen was measured by a nano-type reagent spectrophotometric method, and the permanganate index was measured by an acid method specified 
in [13]. The comprehensive index $\mathrm{I}_{\text {odor }}$ for the measures of varying degrees of odor in river water can be formulated as follows [12]:

$\mathrm{I}_{\text {odor }}=\left(0.3 \mathrm{COD}_{\mathrm{Mn}}+\mathrm{NH} 3-\mathrm{N}\right) /(\mathrm{DO}+6)$

in which $\mathrm{COD}_{\mathrm{Mn}}, \mathrm{NH} 3-\mathrm{N}$ and $\mathrm{DO}$ are all measured in the unit of $\mathrm{mg} \mathrm{L}^{-1}$. Table 1 shows the odor classification associated with the comprehensive index $\mathrm{I}_{\text {odor }}$.

Table 1 The malodorous index and odor classification

\begin{tabular}{ccc}
\hline No & Comprehensive index & Degree of odor \\
\hline 1 & $\mathrm{I}_{\text {odor }}<1.0$ & Odor free \\
2 & $1.0 \leq \mathrm{I}_{\text {odor }}<2.0$ & Slight odor \\
3 & $2.0 \leq \mathrm{I}_{\text {odor }}<5.0$ & Medium odor \\
4 & $\mathrm{I}_{\text {odor }} \geq 5.0$ & Severe odor \\
\hline
\end{tabular}

Sample collection and analysis. Two rivers, named River Jinjiacao and River Sunma, were selected to examine the proposed evaluation approach. Both rivers were located in Ningbo, Zhejiang Province, China where industrialization and rapid economic development have occurred in the last 20 years. The main pollution sources were from industrial and domestic sewage discharge. Samples were taken from the rivers, twice a month, during the period of 2013-2014. Dissolved oxygen in water was measured on the spot using a portable device (Seven2Go S4, China). Two sampling points at the upstream and downstream of the river at the depth of $0.5 \mathrm{~m}$ were used for collecting samples. Samples were stored in a refrigerator with the temperature of $4{ }^{\circ} \mathrm{C}$, and the lab analyses were subsequently carried out within $24 \mathrm{~h}$.

Evaluation of sensory characteristics of river water was performed using the approach proposed by Fang et al. [14]. The points for sensory examination were located at $1 \mathrm{~m}$ from the river, the river bank and the surface of river water. Slight odor, medium odor and severe odor were recorded as one could sense odor at the surface of river water, at the river bank and at $1 \mathrm{~m}$ from the river, respectively.

\section{Results and Discussion}

Calculations of the comprehensive index $\mathrm{I}_{\text {odor }}$ using Eq 1 were performed for River Jinjiacao and River Sunma based on the measurements. Table 2 shows the results of the measured items together with the index $\mathrm{I}_{\text {odor }}$ for River Jinjiacao as an example. The results for River Sunma were not shown in the paper due to the space restriction.

Table 2 The calculated malodorous index and sensory evaluation of malodorous for River Jinjiacao

\begin{tabular}{|c|c|c|c|c|c|}
\hline \multirow[b]{2}{*}{ Date } & \multicolumn{4}{|c|}{ Measurements and index $\mathrm{I}_{\text {odor }}$} & \multirow{2}{*}{$\begin{array}{c}\text { Agreement with } \\
\text { sensory examination? }\end{array}$} \\
\hline & $\begin{array}{l}\mathrm{COD}_{\mathrm{Mn}} \\
\left(\mathrm{mg} \mathrm{L}^{-1}\right)\end{array}$ & $\begin{array}{l}\mathrm{NH}_{3}-\mathrm{N} \\
\left(\mathrm{mg} \mathrm{L}^{-1}\right)\end{array}$ & $\begin{array}{c}\mathrm{DO} \\
\left(\mathrm{mg} \mathrm{L}^{-1}\right)\end{array}$ & $\mathrm{I}_{\text {odor }}$ & \\
\hline 2012.09 & 19.56 & 17.92 & 3.82 & 2.42 & $\mathrm{Y}$ \\
\hline 2012.10 & 16.55 & 16.22 & 3.07 & 2.34 & $\mathrm{Y}$ \\
\hline 2012.11 & 17.40 & 12.91 & 3.78 & 1.85 & $\mathrm{Y}$ \\
\hline 2012.12 & 15.80 & 10.40 & 3.80 & 1.54 & $\mathrm{Y}$ \\
\hline 2013.01 & 13.80 & 8.97 & 3.60 & 1.37 & $\mathrm{Y}$ \\
\hline 2013.02 & 12.77 & 8.79 & 3.51 & 1.33 & $\mathrm{Y}$ \\
\hline 2013.03 & 12.50 & 8.57 & 3.82 & 1.25 & $\mathrm{Y}$ \\
\hline 2013.04 & 14.68 & 10.77 & 3.66 & 1.57 & $\mathrm{Y}$ \\
\hline 2013.05 & 15.93 & 8.76 & 3.98 & 1.36 & $\mathrm{Y}$ \\
\hline 2013.06 & 14.12 & 8.06 & 3.30 & 1.32 & $\mathrm{Y}$ \\
\hline 2013.07 & 15.84 & 8.95 & 4.05 & 1.36 & $\mathrm{Y}$ \\
\hline 2013.08 & 14.57 & 7.44 & 4.82 & 1.09 & $\mathrm{Y}$ \\
\hline 2013.09 & 12.77 & 8.17 & 3.99 & 1.20 & $\mathrm{Y}$ \\
\hline
\end{tabular}




\begin{tabular}{lccccc}
\hline 2013.10 & 12.58 & 8.64 & 3.61 & 1.29 & $\mathrm{Y}$ \\
2013.11 & 12.13 & 8.22 & 4.37 & 1.14 & $\mathrm{Y}$ \\
2013.12 & 13.17 & 7.94 & 3.89 & 1.20 & $\mathrm{Y}$ \\
2014.01 & 12.71 & 7.71 & 4.12 & 1.14 & $\mathrm{Y}$ \\
2014.02 & 11.44 & 6.90 & 4.10 & 1.02 & $\mathrm{~N}$ \\
2014.04 & 9.39 & 10.31 & 4.25 & 1.28 & $\mathrm{Y}$ \\
2014.05 & 14.03 & 9.81 & 4.19 & 1.38 & $\mathrm{Y}$ \\
2014.06 & 9.62 & 6.46 & 4.98 & 0.85 & $\mathrm{Y}$ \\
2014.07 & 11.99 & 7.56 & 5.27 & 0.99 & \\
\hline
\end{tabular}

From Table 2, it is clear that the calculated index $\mathrm{I}_{\text {odor }}$ generally agrees with the sensory evaluation. For River Jinjiacao amongst all the 22 measurement dates, only on two occasions (April and January 2014) the calculated $I_{\text {odor }}$ value did not reflect the reality. On both occasions the calculated $\mathrm{I}_{\text {odor }}$ value indicated slight odor of river water, while no odor was detected during the measurements. In the case of River Sunma, the results are similar. There were 3 occasions in October 2012, January 2014, June 2014 and July 2014 the calculated index Iodor did not agree with the measurements. Overall the accuracy of the calculated $\mathrm{I}_{\text {odor }}$ value for indicating the degree of odor in river water was $91.7 \%$ for River Jinjiacao and $83.3 \%$ for River Sunma, respectively. It is reasonable to conclude, based on the results from this study, that the index $\mathrm{I}_{\text {odor }}$ was correctly formulated, and thus could objectively be used for assessing malodorous rivers.

Nowadays, it is common to have malodorous rivers in urban areas in China, especially in the cities where the rapid economic development was experienced. The traditional approach for the classification for surface water was over simplified [4]. The approach we used in this study for malodorous rivers could be used to quantitatively analyze the interaction between multiple factors controlling water quality. Such an approach could form an important basis for studying the cause of formation of polluted water and assessing the severity of water pollution.

\section{Summary}

Based on the results presented the above, the following conclusions could preliminarily be drawn:

- The comprehensive index is sufficiently accurate to assess malodorous rivers. For the cases studied in this study, the accuracy of prediction reached to $91.7 \%$ and $83.3 \%$, respectively.

- The combined approach of sensory evaluation and malodorous index is objective and effective for evaluating malodorous rivers, and could therefore be used for further classification of inferior Grade V surface water.

\section{Acknowledgements}

The authors wish to thank undergraduate students Lijia Lin, Jiawei Cai, Jiabin Gu, Ruhong Wang, Xia Pan, Zhengning Xiao and Ying Yang who helped carry out lab analyses of water samples.

\section{References}

[1] B. Cees, J. Zoeteman and G.J. Piet: The Science of the Total Environment. Vol. 3 (1974), pp. 103-115.

[2] Z.P. Xu, J.P. Zhang, Z.L. Liao and L.K. Liu: Urban Environmet and Urban Ecology. Vol. 18 (2005), pp. 1-3.

[3] P. Julien, R. Manuel and S. Jean: Water Research.Vol. 44 (2010), pp. 5847-5856.

[4] C. Liu, Z.B. Hu, X.M. Hao and Y.Y. Bai: Journal of East China Normal University (Natural Science). (2011), pp. 43-54.

[5] M. Zhang and J.W. Yang: Shanghai Environment Sciences. Vol. 23 (2004). pp. 161-163.

[6] Y.B. Yu and Y. Huang: Environmental Science and Technology. Vol. 23 (2010), pp. 111-114. 
[7] J. Cheng, E.N. Wu, Y. Che and Q.X. Xu: China Water and Wastewarter. Vol. 22 (2006), pp. $18-22$.

[8] A. Peter, Q. Koster, A Schildkecht and U. von Gunten: Water Research. Vol. 43 (2009), pp. 2191-2200.

[9] Information on http://jcs.mep.gov.cn

[10] Y.H. Chen: PhD Thesis. East China Normal University. (2013), 1-112 pp.

[11] L. Xiao, W.T. Zhao, J.S. Luan, W.Q. Li and D.H. Yang: Journal of Anhui Agriculture Science. Vol. 42 (2014), pp. 9116-9120.

[12] J.H. Xu and Y.P. Hao: Study on the Evaluation Approach of Urban Malodorous-black River. China Environmental Science Press (2009).

[13] State Environmental Protection Administration of China: Water and Wastewater Monitoring Analysis Method. China Environmental Science Press (2002).

[14] Y.C. Fang, Z.N. Qiu, G.Y. Zhang, T.L. Ying and D.Y. Qi: China Environment Science. Vol. 13 (1993), pp. 256-262. 